\title{
Small Fatigue Crack Growth Mechanisms and Interfacial Stability in Cold-Spray 6061 Aluminum Alloys and Coatings
}

\author{
ANASTASIOS G. GAVRAS, DIANA A. LADOS, VICTOR K. CHAMPAGNE, \\ ROBERT J. WARREN, and DILEEP SINGH
}

\begin{abstract}
Cold-spray-processed aluminum alloys have static mechanical properties superior to those of aerospace cast alloys, and similar to those of their wrought counterparts, making them good candidates for structural applications. However, their broad and confident use relies upon systematic fatigue crack growth studies to investigate and demonstrate the materials' performance in critical high-integrity components. In this work, the fatigue crack growth behavior in early stages (small crack growth regime) was investigated for cold-spray processed 6061 aluminum alloys and coatings, at stress ratio $R=0.1$, in room temperature laboratory air. The effects of the characteristic microstructure and initial flaw size on the fatigue crack growth response were systematically examined, and the crack growth mechanisms at the microstructural scale were established and compared to those of long cracks. The mechanical interfacial stability of coatings was examined in cold-spray 6061-rolled 6061-T6 couples. An original method of quantifying the deposition-substrate interfacial strength, and correlating it to the response under cyclic loading via crack-interface stability maps, was developed. The proposed methodology is based on combined scratch testing and fracture mechanics formulations, and failure at the coating-substrate interface can be predicted for any crack growth scenario under cyclic loading. The method can be broadly used for the design and optimization of cold-spray and other coatings, as well as in structural repair.
\end{abstract}

https://doi.org/10.1007/s11661-018-4929-0

(C) The Author(s) 2018

\section{INTRODUCTION AND BACKGROUND}

SURFACE properties have a significant effect on the performance of metallic materials under dynamic loading, corrosion, and extreme environments. Cold-spray processing is a material deposition process where the temperature of the gas stream is always below the melting point of the particulate material, meaning that the feedstock remains in the solid state throughout the entire application. ${ }^{[1]}$ It is the solid state nature of the process that sets cold-spray apart from conventional thermal spray techniques, and there are several advantages associated with the low processing temperatures. There is little oxidation, and no deleterious stresses that

ANASTASIOS G. GAVRAS, DIANA A. LADOS, and ROBERT J. WARREN are with the Worcester Polytechnic Institute, Integrative Materials Design Center, Worcester, MA 01609. Contact e-mail: r.j.warren@swansea.ac.uk VICTOR K. CHAMPAGNE is with the U.S. Army Research Laboratory, Aberdeen Proving Ground, Aberdeen, MD 21005. DILEEP SINGH is with the Argonne National Laboratory, Argonne, IL 60439.

Manuscript submitted January 3, 2018.

Article published online October 15, 2018 occur due to thermal contraction, which allows thicker coatings and actual structural parts to be built through this technique. Cold-spray materials do not exhibit segregation, a phenomenon which is often observed during thermal spray, and as a result, the material properties remain uniform. ${ }^{[2,3]}$ There is also low heat delivered into the workpiece, meaning no complex cooling is required, making cold-spray an excellent method for structural repair.

Cold-spray depositions are achieved by accelerating powder feedstock via a heated, high-pressure gas stream (typically nitrogen or helium) through a converging-diverging de Laval nozzle towards the substrate at very high velocities, up to $1500 \mathrm{~m} / \mathrm{s}$ depending on the material, as shown schematically in Figure 1.

Upon impact with the substrate, the powder particles are plastically deformed, and once a critical impact velocity is reached, bonding occurs due to adiabatic shear instability, ${ }^{[5-8]}$ yielding a deposit with low porosity, high particle-to-particle bond strength, and increased cohesive strength with the substrate. Coating-substrate adhesion is achieved due to differing material viscosities, which, along with the resulting interfacial roll-ups and vortices, increase the interfacial 
area, giving rise to material mixing and providing a mechanical interlock between the coating and substrate. ${ }^{[9,10]}$ Another critical consideration regarding the deposition adhesion is the evaluation of the diffusion-based metallurgical bonding of the coating to the substrate, which depends on the material, temperature upon impact, and resident time at temperature. Thus, there are several important parameters that govern both the particle bonding of the deposition, as well as its adhesion to the workpiece, including process temperature, gas conditions, nozzle geometry, type of sprayed material, and the powder characteristics such as particle velocity, density, morphology, and distribution. ${ }^{4,11]}$

Due to the low temperatures and high impact velocities during processing, cold-spray deposits are typically made up of a very fine microstructure, which is in state of compressive residual stress. ${ }^{[12,13]}$ It follows that cold-spray coatings are an effective means to improve the fatigue strength of the materials, with increases from 15 to 30 pct reported in several studies. ${ }^{[14-19]}$ However, there is little to no published work regarding the fatigue crack growth behavior and mechanisms at the microstructural scale for cold-spray deposits and coatings. Fatigue cracks can be classified as mechanically small (comparable in size to local plasticity), microstructurally small (comparable in size to relevant microstructural characteristic dimensions), physically small (cracks not affected by closure, typically less than 1-2 $\mathrm{mm}$ in length), and long (affected by closure in the near-threshold regime). ${ }^{[20-22]}$ The difference between "long" and "small" fatigue crack growth is very important, especially in the near-threshold crack growth regime, as reported for a series of Al-Si-Mg cast alloys, ${ }^{[23]}$ and it significantly affects the high-cycle fatigue behavior of the material. A previous study by the authors investigated the long fatigue crack growth mechanisms in bulk deposited cold-spray 6061 aluminum. ${ }^{[2]}$ This study was designed to expand the

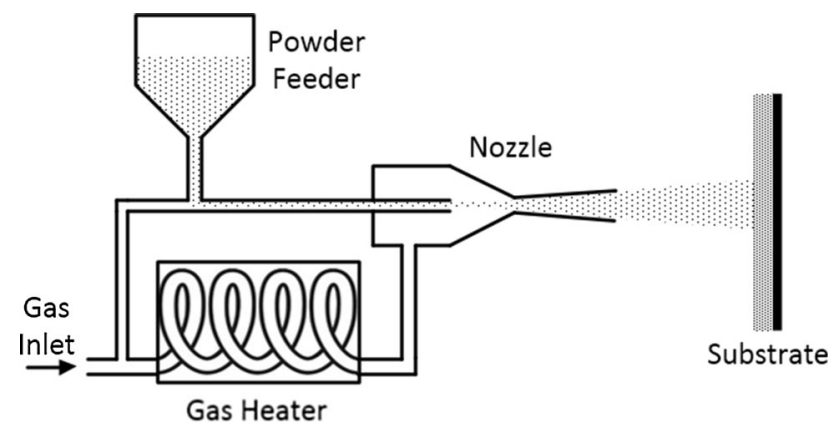

Fig. 1-Schematic of the cold-spray deposition process. Adapted from Ref. [4]. previous work by examining the microstructurally small to physically small fatigue crack growth behavior in bulk cold-spray 6061 deposits, as well as cold-spray 6061 coatings on substrates. Thus, the controlling fatigue crack growth mechanisms in early stages are determined, and the strength at the coating-substrate interface is investigated. Unique fracture mechanics formulations were developed to characterize the small crack growth behavior, and the crack interaction with the deposition-coating interface, based on the material condition and initial flaw size. Original crack-interface stability maps are also provided, which are important tools for component design and material/cold-spray process optimization.

\section{METHODOLOGY}

\section{A. Materials and Processing}

The powder used by the Army Research Labs (ARL) for the preparation of the cold-spray 6061 depositions was provided by Valimet. The pre-alloyed powder had a mean particle diameter of $25 \mu \mathrm{m}( \pm 15 \mu \mathrm{m})$, and the chemical composition is given in Table I. The substrate material used in this study was rolled 6061 aluminum plate, with the chemical composition also given in Table I. It is likely that the powder particles will have some degree of surface oxidation; however the brittle nature of the oxides, combined with the deformation of each particle during deposition, result in the oxide films breaking up, allowing for favorable particle bonding with the substrate and other particles. ${ }^{[25,26]}$

The rolled 6061 plate was used in the T6 temper, with a grain structure consisting of recrystallized "pancake" grains, as shown in Figure 2(a). The microstructure, Figures 2(a) and (d), consists of the $\alpha$-Al Matrix, the $\mathrm{Mg}_{2} \mathrm{Si}$ precipitate phase, the $\mathrm{Al}_{x} \mathrm{Fe}_{y} \mathrm{Si}_{z}$ phase fragmented during the rolling process, and the small $\mathrm{Al}_{12}(\mathrm{FeCrMn})_{3} \mathrm{Si}$ dispersoids. The substrate and nozzle characteristics, as well as the deposition parameters, have been introduced in Reference 24 and are summarized in Table II.

The X-ray diffraction analysis of the deposit, showed that the powder's microstructure was not affected by the cold-spray process. ${ }^{[24]}$ It should be noted that the particle structure was examined in all three dimensions for the cold-spray 6061 alloys, Figures 2(b) and (c), to verify the material's isotropy. The cold-spray particle size was measured using the mean linear intercept method according to the ASTM-E112-12 standard. ${ }^{[27]}$ The cold-spray 6061 alloys were evaluated in the as-sprayed condition, as well as after annealing at $617 \mathrm{~K}\left(344^{\circ} \mathrm{C}\right)$ for 8 hours. The microstructures of the

Table I. Chemical Composition (in Weight Percent) of Cold-Spray and Rolled 6061 Aluminum Alloys

\begin{tabular}{lccccccccc}
\hline Alloy & $\mathrm{Mg}$ & $\mathrm{Si}$ & $\mathrm{Fe}$ & $\mathrm{Cu}$ & $\mathrm{Mn}$ & $\mathrm{Cr}$ & $\mathrm{Ti}$ & Others & Al \\
\hline Cold-Spray 6061 & 1.01 & 0.61 & 0.30 & 0.25 & 0.04 & 0.09 & 0.02 & 0.08 & bal. \\
Rolled 6061 & 0.90 & 0.64 & 0.38 & 0.26 & 0.03 & 0.21 & 0.02 & 0.05 & bal. \\
\hline
\end{tabular}




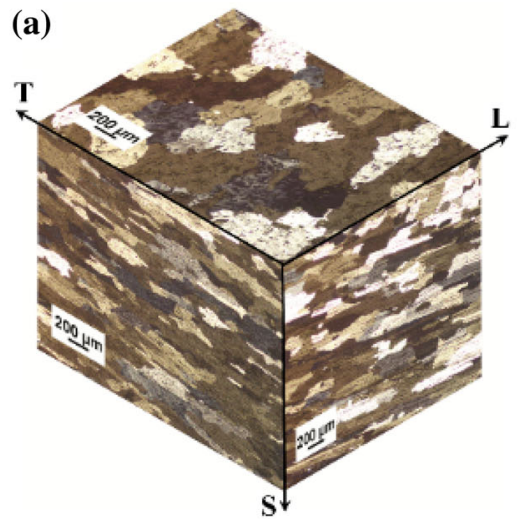

Substrate rolled 6061-T6

Grain size: $183 \mu \mathrm{m}$ x $551 \mu \mathrm{m}$

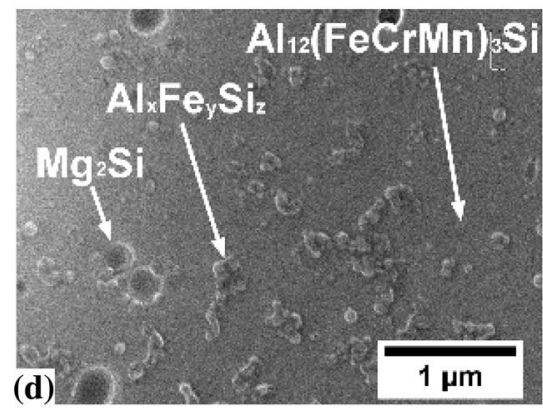

Substrate rolled 6061-T6

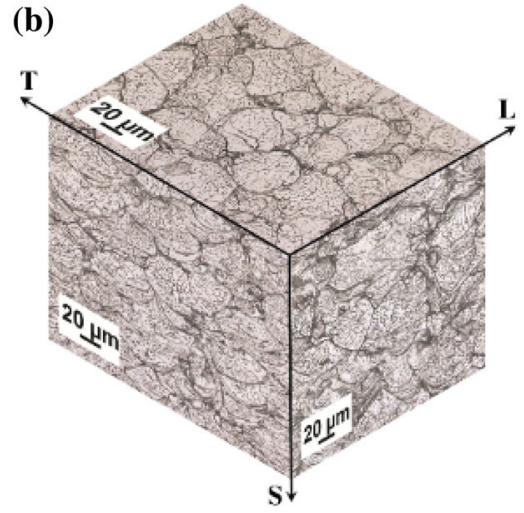

Cold-spray 6061

Mean Particle Size: $27.0 \mu \mathrm{m}$

Standard Deviation: $15.2 \mu \mathrm{m}$

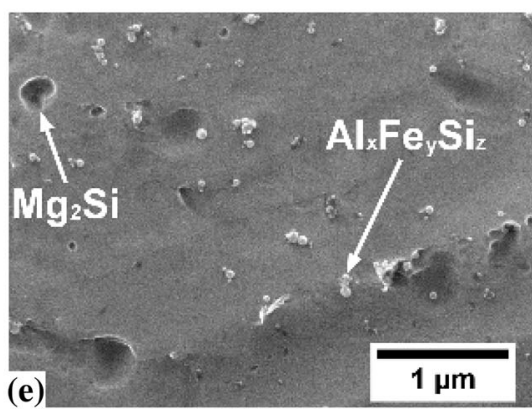

Cold-spray 6061

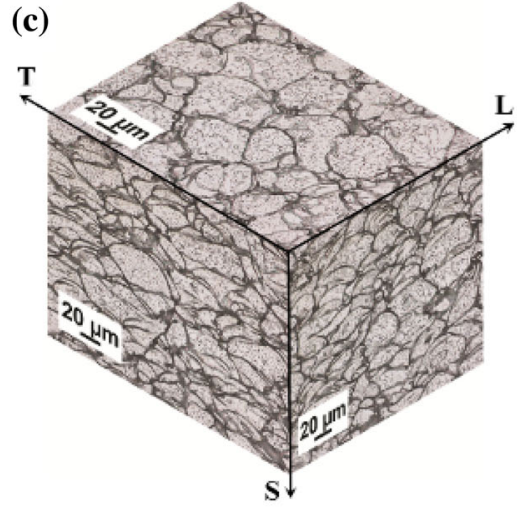

Annealed cold-spray 6061

Mean Particle Size: $31.7 \mu \mathrm{m}$

Standard Deviation: $13.9 \mu \mathrm{m}$

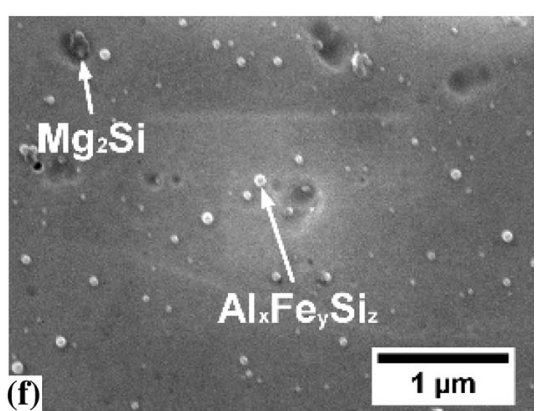

Annealed cold-spray 6061

Fig. 2- $(a-c)$ Grain structures and $(d-f)$ secondary, precipitate, and dispersoids phases of rolled 6061-T6 plate substrate and as-sprayed and annealed cold-spray 6061 alloys. Reprinted from Ref. [24].

Table II. Substrate and Nozzle Characteristics and Deposition Parameters ${ }^{[24]}$

\begin{tabular}{ll}
\hline $\begin{array}{l}\text { Substrate } \\
\text { Material }\end{array}$ & 6061 aluminum \\
Substrate Grit Blasting & 60 grit at $414 \mathrm{kPa}$ \\
Substrate Cleaning & alcohol and air \\
Nozzle & \\
Throat Diameter & $0.0026 \mathrm{~m}$ \\
Weight & $0.0647 \mathrm{~g}$ \\
Deposition Parameters & helium \\
Gas Type & $2000 \mathrm{kPa}$ and $3.0 \mathrm{~m}^{3} /$ hour \\
Gas Pressure and Flow & gun at $400{ }^{\circ} \mathrm{C}$ and pre-heater \\
Heater Set Points & at $350^{\circ} \mathrm{C}$ \\
& $1.3 \mathrm{rpm}$ and $13 \mathrm{~m}^{3} /$ hour \\
Powder Feed Actual & $0.028 \mathrm{~m}$ \\
Spray Distance & $1 \mathrm{~m} / \mathrm{s}$ \\
Spray Gun Velocity & \\
\hline
\end{tabular}

as-sprayed and annealed materials are shown in Figures 2(b), (c), (e), and (f), where the prior particle boundaries can be easily seen due to the etching process used (described later). This should not be assumed to be indicative of any continuous oxide layers, which would have been broken up during the deposition process. Scanning electron microscope (SEM) and Energydispersive X-ray spectroscopy (EDS) analysis techniques were used to ascertain the microstructural phases present in the alloys. The observations were in agreement with the computer simulations conducted in JMat Pro and Thermo-Calc, and are consistent with observations in the literature. ${ }^{[28,29]}$ The microstructure of the as-sprayed 6061 alloy, Figures 2(b) and (e), consists primarily of the $\alpha$-Al matrix, the $\mathrm{Mg}_{2} \mathrm{Si}$ precipitate phase within the matrix (darker particles), and a mixture of the particle-shaped and acicular iron-containing $\mathrm{Al}_{x} \mathrm{Fe}_{y} \mathrm{Si}_{z}$ phases (lighter particles) primarily located along particle/grain boundaries. The precise stoichiometry of the phases is dependent on the alloy composition, and is not established in this study. In the annealed cold-spray 6061, Figure 2(c) and (f), the $\mathrm{Mg}_{2} \mathrm{Si}$ phase remains unaltered, but some of the acicular $\mathrm{Al}_{x} \mathrm{Fe}_{y} \mathrm{Si}_{z}$ phase has transformed into an equiaxed/round-shaped $\mathrm{Al}_{x} \mathrm{Fe}_{y} \mathrm{Si}_{z}$ phase. The annealed cold-spray material may also contain small amounts of very fine $\mathrm{Al}_{12}(\mathrm{FeCrMn})_{3} \mathrm{Si}$ dispersoids, although these typically form at temperatures above $648 \mathrm{~K}\left(375^{\circ} \mathrm{C}\right)$.

\section{B. Hardness, Tensile, and Fatigue Crack Growth Testing}

Microindentation Vickers hardness measurements were made using a TUKON 1202 tester using a load of $100 \mathrm{gf}$ applied for 10 seconds. The Vickers hardness values reported in this study are each average values of 15 individual measurements conducted in accordance with ASTM E384. ${ }^{[30]}$ 
The specimens used for tensile testing, Figure 3(a), were machined with a gage length of $25 \mathrm{~mm}$ and a gage width of $6 \mathrm{~mm}$. The overall specimen length was $100 \mathrm{~mm}$ in order to provide an adequate grip area for testing. Tensile tests for all materials were conducted according to ASTM E8/E8M-16a ${ }^{[31]}$ at room temperature, in laboratory air, using a constant extension rate of $0.015 \mathrm{~mm} / \mathrm{s}$; the strain was measured by an extensometer.

Long and small fatigue crack growth tests were both performed in this study at room temperature in laboratory air. Long fatigue crack growth experiments were conducted using compact tension, $\mathrm{C}(\mathrm{T})$, specimens, shown in Figure 3(b). The rolled 6061-T6 C(T) specimens had a thickness, $B$, of $10.2 \mathrm{~mm}$ and a width, $W$, of $50.8 \mathrm{~mm}$. The as-sprayed and annealed cold-spray 6061 $\mathrm{C}$ (T) specimens had a thickness, $B$, of $10.2 \mathrm{~mm}$ with a reduced width, $W$, of $33.0 \mathrm{~mm}$ due to original build's size constraints. These specimens were machined according to the ASTM-E647 standard, and they were both in compliance with the elastic requirement for all values of applied force. ${ }^{[32]}$ The notch lengths (measured from the center of the pinholes) were $6.6 \mathrm{~mm}$ and $10.2 \mathrm{~mm}$ for the smaller and larger specimens, respectively. The notch was introduced using wire-cut electrical discharge machining $(\mathrm{EDM})$, and its thickness was $0.254 \mathrm{~mm}$. Long fatigue crack growth tests were conducted in accordance with ASTM-E647, ${ }^{[32]}$ at three constant stress ratios $(0.1,0.5$, and 0.7$)$. The decreasing $K$ method, with a $K$ gradient of $-5.5(\mathrm{MPa} \sqrt{\mathrm{m}}) / \mathrm{m}$ and frequency of 20 $\mathrm{Hz}$, was used to generate the low Region II and near-threshold fatigue crack growth response. An increasing $K$, with a $K$ gradient of $+5.5(\mathrm{MPa} \sqrt{\mathrm{m}}) / \mathrm{m}$ and frequency of $20 \mathrm{~Hz}$, was used to obtain the middle and upper Region II and Region III fatigue crack growth response. Above a crack growth rate of $2.5 \times 10^{-4} \mathrm{~mm} /$ cycle, the tests were concluded under constant load and a reduced frequency of $5 \mathrm{~Hz}$ in order to capture sufficient data towards the end of the tests. Crack length was measured using the compliance method. For long fatigue crack growth in the near-threshold regime, crack closure can significantly affect the crack-tip stress intensity factor range, $\Delta K$, particularly at low stress ratios. ${ }^{[33,34]}$ In this study, the adjusted compliance ratio (ACR) method was used to calculate the effective, closure-corrected, stress intensity values $\left(\Delta K_{\text {eff }}\right)$. The ACR method ${ }^{[35]}$ is a crack closure measurement technique that accounts for the contribution to fatigue crack growth of cyclic crack-tip strain below the opening load, and has been shown to produce accurate, reliable results. ${ }^{[36]}$

Small fatigue crack growth experiments on both the rolled 6061-T6 and cold-spray alloys were performed on surface flaw tension, $\mathrm{SF}(\mathrm{T})$, specimens, Figure 3(c). The $\mathrm{SF}(\mathrm{T})$ specimens had a gage cross section of 10.2 $\mathrm{mm} \times 5.1 \mathrm{~mm}$. The initial semi-circular flaw radius (also machined by wire-cut EDM) varied from 120 to $150 \mu \mathrm{m}$, depending on the size of the materials' characteristic microstructures. The small fatigue crack growth tests were conducted in accordance with ASTM-E647 in laboratory air at room temperature, under constant load, and a stress ratio $R=0.1$, using a cyclic frequency of $20 \mathrm{~Hz}$. To establish the fatigue crack growth threshold, the test was started at a $\Delta K$ level well below the estimated threshold, and $\Delta K$ was increased in a step-like fashion, by increasing the load, until crack growth from the EDM starter flaw was detected. The direct current potential drop (DCPD) method was used to measure the crack length throughout the test.

In addition to the fatigue crack growth specimens of the bulk cold-spray 6061 alloys, a rolled 6061-T6 SF(T) specimen with the same dimensions was coated with cold-spray 6061. This specimen was used for the interfacial studies, where a small fatigue crack was designed to grow from a semi-circular EDM flaw (radius $\sim 120 \mu \mathrm{m}$ ) in the cold-spray 6061 coating, through the interface, and into the rolled 6061-T6 substrate. The thickness of the applied coating was approximately 150 $\mu \mathrm{m}$. All test conditions for this case were kept consistent with the bulk small fatigue crack growth tests.

\section{Adhesion Strength Scratch Testing}

Scratch testing was performed on cold-spray-coated 6061-T6 blocks that were $25 \mathrm{~mm}$ long and $12.5 \mathrm{~mm}$ wide, with a cold-spray coating thickness of $200 \mu \mathrm{m}$.

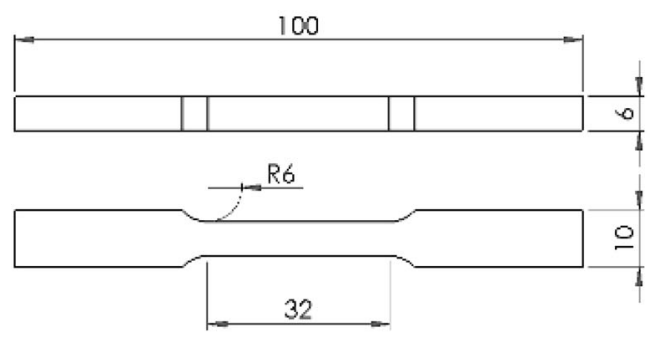

(a)

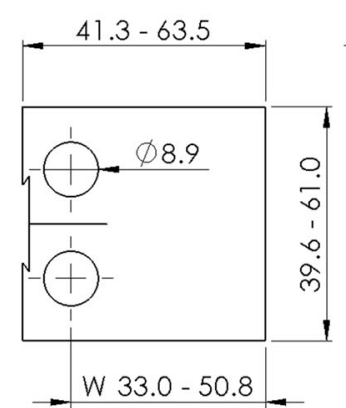

(b)

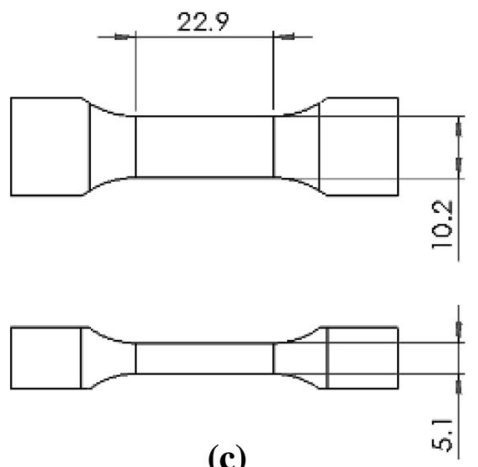

(c)

Fig. 3-Schematic drawings of (a) tensile bar specimen, (b) $\mathrm{C}(\mathrm{T})$ specimen used for long fatigue crack growth experiments, and (c) SF(T) specimen used for small fatigue crack growth experiments; drawings not to scale, all measurements are in $\mathrm{mm}$. 
Since the ductility of the coating is suitably low, tests were performed according to the ASTM-C1624 standard test method for determining the adhesion strength and mechanical failure modes of ceramic coatings by quantitative single-point scratch testing. ${ }^{[37]}$ A Rockwell C diamond stylus with $125 \mu \mathrm{m}$ radius was used to penetrate the coating at a loading rate of $3 \mathrm{~N} / \mathrm{s}$. The acoustic signals, transverse and normal loads, and friction coefficient were monitored during the scratch tests. The critical load at which the coating started to fail was determined based on distinct acoustic events, and correlated to spallation observed on the scratch track using optical microscopy. A schematic representation of the scratch testing is shown in Figure 4.

\section{Metallographic Preparation and Fractography}

Metallographic specimens were prepared according to ASTM E3-11 ${ }^{[38]}$ and the Buehler SumMet materials preparation guide. ${ }^{[39]}$ Specimens were sectioned using an abrasive wet cutting wheel. The cut sections were then mounted in conductive Bakelite, and ground and polished using an auto polisher, before being etched by immersing in Keller's reagent ( 95 pct water, 2.5 pct $\mathrm{HNO}_{3}, 1.5$ pct $\mathrm{HCl}, 1.0$ pet HF) for 10 seconds. Optical micrographs were captured using a Nikon MA 200 Eclipse microscope, and image analysis was performed using the Elements D software. To establish the fatigue crack propagation mechanisms, fracture surfaces were examined using a JEOL-7000F SEM, and subsequently sectioned, mounted, polished, and etched for optical examination of the crack path along the median section.

\section{RESULTS AND DISCUSSION}

\section{A. Tensile Properties}

Tensile properties measured per ASTM-E ${ }^{[31]}$ for all studied alloys were depicted previously, ${ }^{[24]}$ and are presented in Table III as reference for the subsequent analytical modeling. The as-sprayed 6061 alloy has similar yield and tensile strengths to the rolled 6061 alloy in the T6 temper. However, the elongation at failure is limited to approximately 2 pct. Annealing of the cold-spray 6061 alloy improves the percent elongation at failure from 2.0 to $13.0 \mathrm{pct}$ at the expense of yield

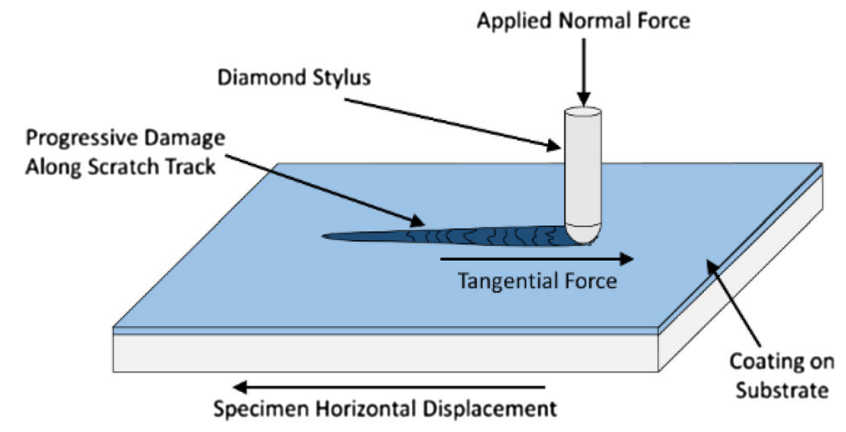

Fig. 4-A schematic representation of the scratch test. From Ref. [37] with permission. and tensile strengths, which decrease by 44 and 32 pct, respectively.

\section{B. Long and Small Fatigue Crack Growth Data and Mechanisms}

Long and small fatigue crack growth data at $R=0.1$, for the annealed 6061 cold-spray and rolled 6061-T6 alloys, are presented and compared in Figure 5. Small fatigue crack growth applied data for both cold-spray and rolled alloys are characterized by lower threshold values and higher crack growth rates in Regions I and II compared to the corresponding long fatigue crack growth applied data, Figure 5(a). The applied and effective (after ACR corrections) $\Delta K_{\text {th }}$ and $\Delta K_{\max }$ values, as well as Paris constants $(C$ and $m$ ), for all tested conditions are given in Table IV.

It is interesting to note that the small fatigue crack growth threshold in the case of the annealed 6061 cold-spray is only slightly lower than the long crack growth threshold, whereas for the rolled 6061-T6 alloy, the difference between the long and small thresholds is considerably larger. These differences can be attributed to the significant differences in closure levels between the two materials, Figure 5(b), with the cold-spray material showing less closure due to the intrinsically finer grain structure. In addition, the small fatigue crack growth threshold in the annealed 6061 cold-spray is higher than that of the rolled 6061-T6 alloy, both materials having similar initial crack size $(\sim 120 \mu \mathrm{m})$. The enhanced resistance of the 6061 cold-spray alloys is thought to be due to two main factors, the fine grain structure which results in more grain boundaries that act as barriers to the early stages of transgranular crack growth, and the variations in the local matrix plasticity due to differences in the concentration, distribution, and morphology of the precipitate and dispersoid phases. The small fatigue crack growth rates of both materials become similar in lower Region II, and after a cross-over at $\sim 2 \times 10^{-6} \mathrm{~mm} /$ cycle, the small fatigue crack growth curves merge with their respective long fatigue crack growth curves at $\sim 2 \times 10^{-3} \mathrm{~mm} /$ cycle (annealed coldspray 6061) and $\sim 2 \times 10^{-4} \mathrm{~mm} /$ cycle (rolled 6061-T6).

Representative SEM fractographs from different regions of crack growth, for both long and small cracks, in annealed cold-spray 6061 and rolled 6061-T6 are presented in Figure 6. In the case of long fatigue crack growth in annealed cold-spray 6061, in the near-threshold regime, Figure 6(a), the fracture surface indicates a transparticular (through prior-powder particles) type of propagation, with small facets due to the fracture of the very fine grains within the particles. Near-threshold small fatigue crack growth, Figure 6(e), also exhibits transparticular crack growth. In low Region II, for both long and small crack growth, Figures 6(b) and (f), a mixed mode of crack advance is observed, mainly through the particles, with occasional crack growth through the particle boundaries.

The behavior and mechanisms of long fatigue cracks, at higher $\Delta K$ levels, further indicate a gradual change from a transparticular crack growth mode to an 
Table III. Microhardness, Yield Strength $\left(\sigma_{\mathrm{Y}}\right)$, Ultimate Tensile Strength $\left(\sigma_{\mathrm{UTS}}\right)$, Total Elongation at Failure (el Percent), and Elastic Modulus $(E)$, for All Studied Alloys; All Tests Were Performed in Tension Parallel to the Longitudinal Direction, $L^{[24]}$

\begin{tabular}{lcccrr}
\hline Alloy & Microhardness $\left[\mathrm{HV}_{100}\right]$ & $\sigma_{\mathrm{Y}(0.2 \mathrm{pct})}(\mathrm{MPa})$ & $\sigma_{\mathrm{UTS}}(\mathrm{MPa})$ & Elongation $(\mathrm{el} \mathrm{Percent})$ & $E(\mathrm{GPa})$ \\
\hline Cold-Spray 6061-As-Sprayed & 105.0 & 262.0 & 286.8 & 2.0 \\
Cold-Spray 6061-Annealed & 65.7 & 147.5 & 195.1 & 67.5 \\
Rolled Plate 6061-T6 & 107.0 & 291.6 & 317.1 & 13.0 & 17.0 \\
\hline
\end{tabular}

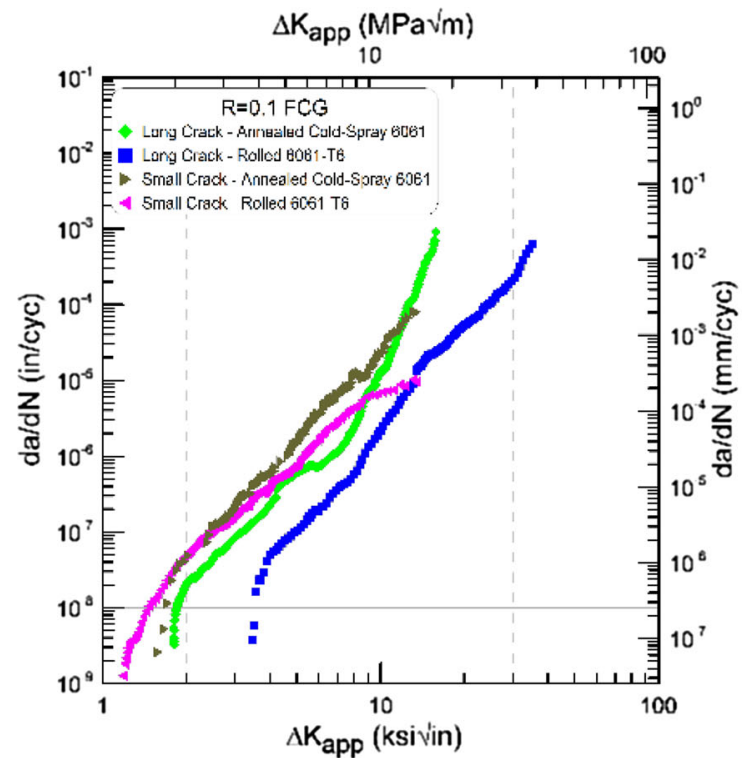

(a)

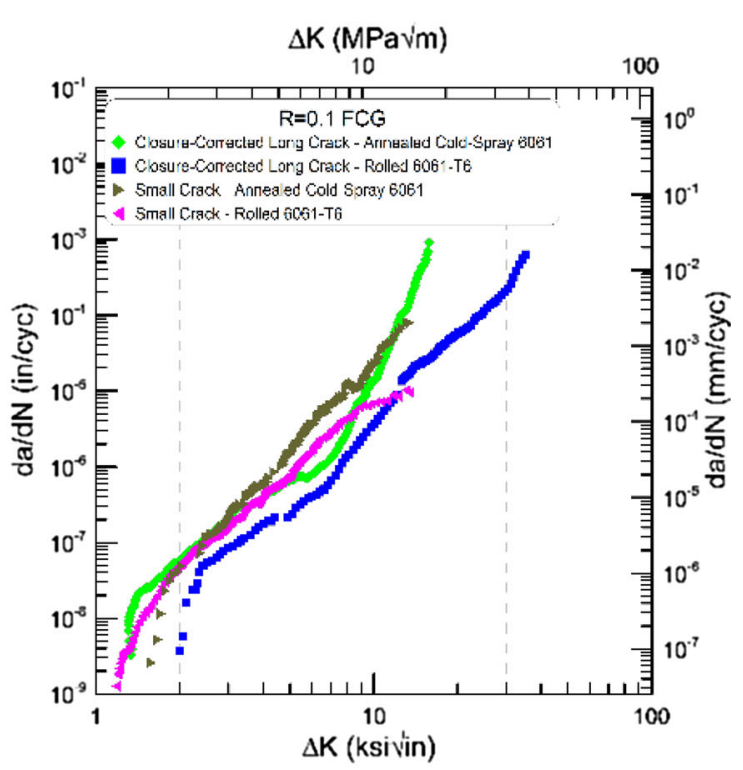

(b)

Fig. 5-Applied (a) and closure-corrected (b) long and small fatigue crack growth data for annealed 6061 cold-spray and rolled 6061-T6 alloys. Long fatigue crack growth data reprinted from Ref. [24] and used here for comparison and further analysis.

Table IV. Summary of Applied and Effective $\Delta K_{\text {th }}$ Values, $\Delta K_{\max }$ Values, and Paris Law Coefficients $(C$ and $m)$ for All Test Conditions in Fig. 5(a)

\begin{tabular}{|c|c|c|c|c|c|c|}
\hline Material & $R$ & $\Delta K_{\text {th-app }}(\mathrm{MPa} \sqrt{ } \mathrm{m})$ & $\Delta K_{\text {th-eff }}(\mathrm{MPa} \sqrt{\mathrm{m}})$ & $\Delta K_{\max }(\mathrm{MPa} \sqrt{\mathrm{m}})$ & $C$ & $m$ \\
\hline C(T) Cold-Spray 6061-Annealed & 0.1 & 2.0 & 1.4 & 17.4 & $1.6 \mathrm{E}-9$ & 3.6 \\
\hline C(T) Rolled 6061-T6 & 0.1 & 3.8 & 2.2 & 38.7 & $7.7 \mathrm{E}-11$ & 4.5 \\
\hline SF(T) Cold-Spray 6061-Annealed & 0.1 & 1.7 & $\mathrm{n} / \mathrm{a}$ & 14.8 & $2.8 \mathrm{E}-9$ & 3.9 \\
\hline SF(T) Rolled 6061-T6 & 0.1 & 1.3 & $\mathrm{n} / \mathrm{a}$ & 14.7 & $4.9 \mathrm{E}-9$ & 3.2 \\
\hline
\end{tabular}

interparticular one, and more details can be found in the authors' previous study. ${ }^{[2]}$

For the near-threshold long crack growth in rolled 6061-T6, Figure 6(c), the fracture surface is transgranular in nature, with a faceted appearance resulting from the crystallographic mode of crack propagation. The near-threshold small crack growth, Figure 6(g), shows a brittle transgranular fracture with very fine facets. In low Region II of long and small crack growth, Figures 6(d) and (h), the fracture surfaces show cleavage planes and steps resulting from the brittle, transgranular crack propagation.

\section{Studies of the Coating-Substrate Interface}

1. Fatigue crack growth behavior through the coating and at the coating-substrate interface

In order to examine the interfacial behavior during cyclic loading, a semi-circular surface flaw was introduced in the as cold-sprayed coating, and a small crack was grown at $R=0.1$, through the coating, through the interface, and into the rolled 6061-T6 substrate material. From the fracture surface and the fracture surface profile, at the median section of the small crack growth $\mathrm{SF}(\mathrm{T})$ specimen, it was observed that the interface between the cold-spray coating and the rolled 6061-T6 


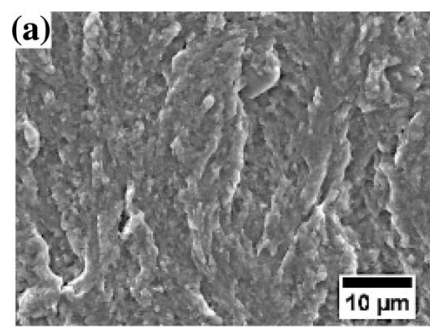

Annealed cold-spray 6061

Long crack threshold

$\Delta K \sim 2.0 \mathrm{MPa} \sqrt{\mathrm{m}}$

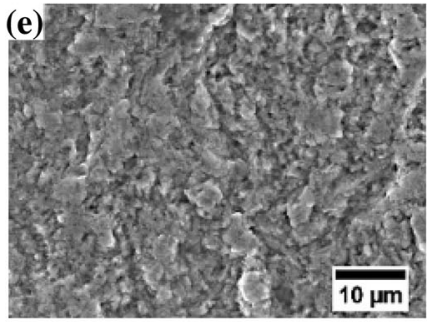

Annealed cold-spray 6061

Small crack threshold

$\Delta K \sim 1.7 \mathrm{MPa} \sqrt{\mathrm{m}}$

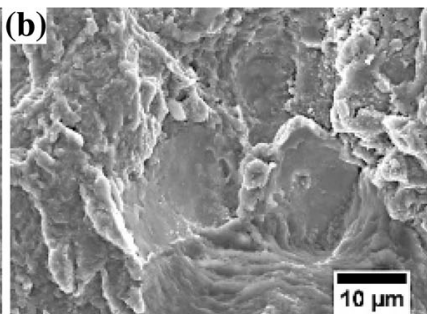

Annealed cold-spray 6061

Long crack low Region II $\Delta K \sim 2.4 \mathrm{MPa} \sqrt{\mathrm{m}}$

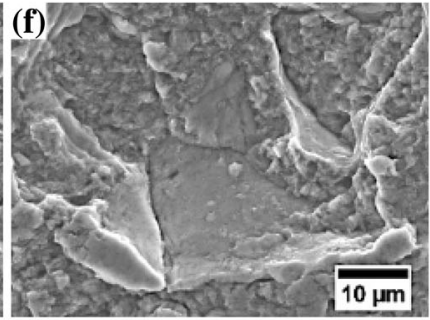

Annealed cold-spray 6061

Small crack low Region II $\Delta K \sim 2.2 \mathrm{MPa} \sqrt{\mathrm{m}}$

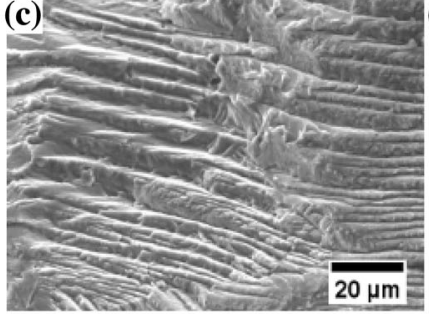

Rolled 6061-T6

Long crack threshold

$\Delta K \sim 3.8 \mathrm{MPa} \sqrt{\mathrm{m}}$

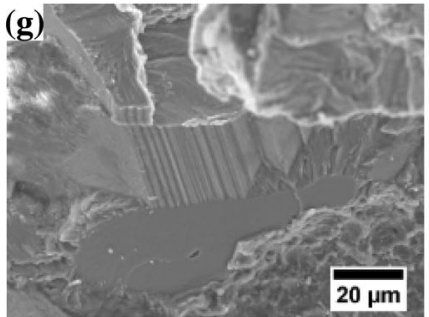

Rolled 6061-T6

Small crack theshold $\Delta K \sim 1.3 \mathrm{MPa} \vee \mathrm{m}$

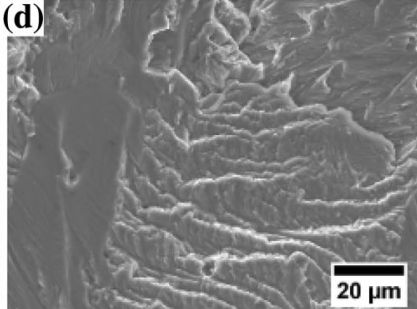

Rolled 6061-T6

Long crack low Region II

$\Delta K \sim 4.5 \mathrm{MPa} \sqrt{\mathrm{m}}$

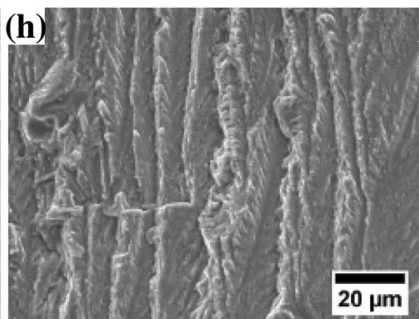

Rolled 6061-T6

Small crack low Region II

$\Delta K \sim 1.6 \mathrm{MPa} \sqrt{\mathrm{m}}$

Fig. 6-SEM fracture surfaces of long crack growth in $(a, b)$ annealed cold-spray 6061 and $(c, d)$ rolled 6061-T6; and small crack growth in $(e, f)$ annealed cold-spray 6061 and $(g, h)$ rolled 6061-T6.
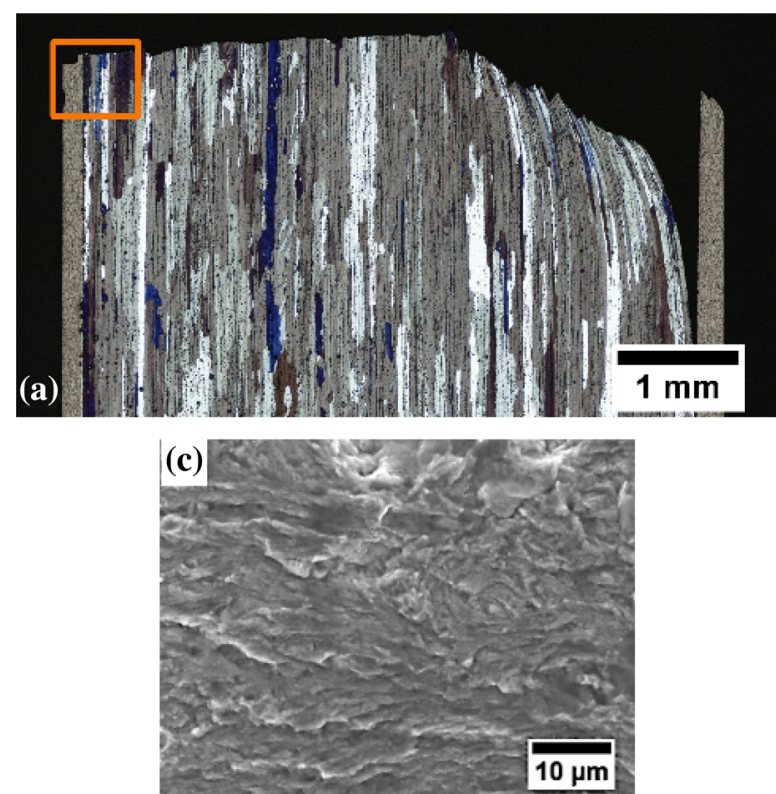

Threshold (as-sprayed 6061 coating) $\Delta K \sim 1.9 \mathrm{MPa} \sqrt{\mathrm{m}}$
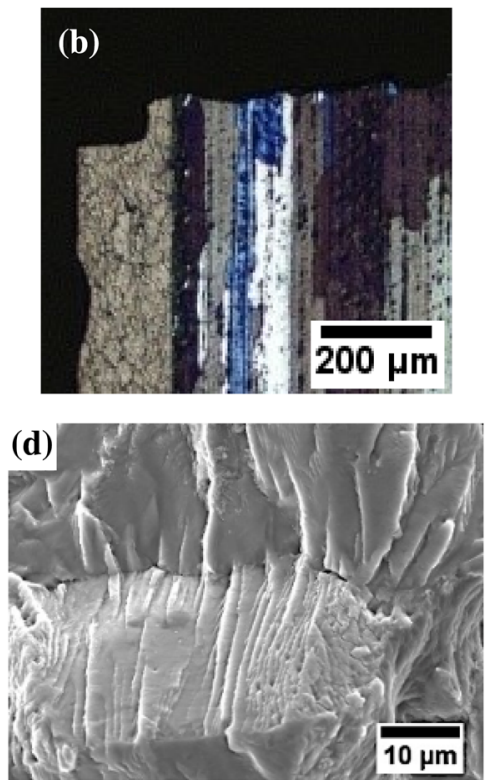

Mid Region II (rolled 6061-T6 substrate) $\Delta K \sim 4.5 \mathrm{MPa} \sqrt{\mathrm{m}}$

Fig. 7- $(a, b)$ Optical images of the median cross section of the cold-spray-coated 6061-T6 SF(T) specimen and $(c, d)$ SEM images of the fracture surface of cold-spray-coated 6061-T6 SF(T) specimen.

substrate material was stable, and no interfacial cracking or delamination occurred during the fatigue crack growth testing, Figure 7(b). Only after completion of the test, where the specimen had been statically overloaded and pulled apart, was delamination of the coating observed, as seen on the right-hand side of Figure 7(a).

The fracture surface of the coated $\mathrm{SF}(\mathrm{T})$ specimen in the near-threshold regime, corresponding to the growth through the as-sprayed coating, indicates a progressive 


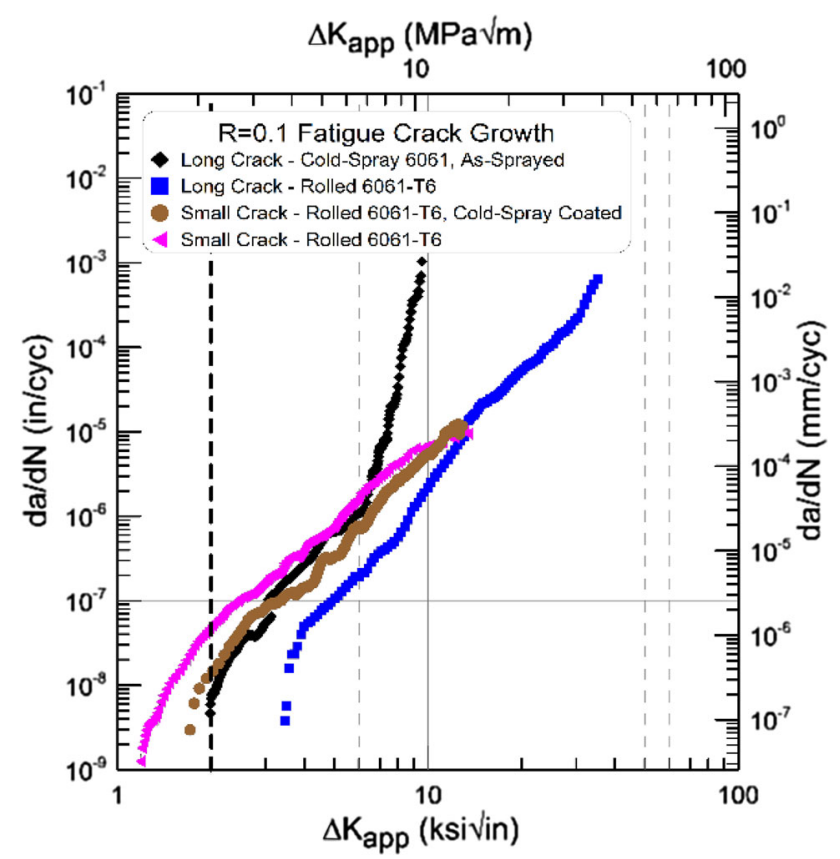

Fig. 8- Small fatigue crack growth data for the cold-spray-coated rolled 6061-T6 specimen and long fatigue crack growth data for as cold-sprayed and rolled 6061; the vertical dashed line represents the crack's transition from the coating to the substrate. advance of the crack in a transparticular grain-related faceted fashion, Figure 7(c), similar to the small crack growth in the annealed material, Figure 6(e). In mid Region II, as the crack transitions into the substrate, a transgranular mode of crack propagation is observed through the rolled 6061-T6 material, with evidence of striations within the $\alpha$-Al matrix, and tilts and twists at grain boundaries, as seen in Figure 7(d). Ductile fracture occurs after pulling the specimen apart statically at the end of the test.

In the case of long fatigue crack growth in the as-sprayed alloys, at low $\Delta K$ values in the near-threshold regime, crack propagation is also transparticular with a smooth fracture surface as described previously. ${ }^{[24]}$ With increasing crack-tip driving force, at higher $\Delta K$ values, a mixed transparticular-interparticular mode of crack propagation is observed until the change to a predominantly interparticular mode occurs in upper Region II, where an extensive damage zone ahead of the crack tip has been developed, facilitating the preferred meandering through the particle boundaries. ${ }^{[24]}$

Figure 8 shows the small fatigue crack growth test data of the cold-spray-coated 6061-T6 SF(T) specimen, compared to long fatigue crack growth test data of the as-sprayed $6061 \mathrm{C}(\mathrm{T})$ specimen, as well as long and small fatigue crack growth test data of the rolled 6061-T6 substrate material. The applied and effective

Table V. Summary of Applied and Effective ACR-Corrected $\Delta K_{\text {th }}$ Values and Paris Law Coefficients $(C$ and $m)$ for All Test Conditions Shown in Fig. 8

\begin{tabular}{lcccc}
\hline Material & $R$ & $\Delta K_{\text {th-app }}(\mathrm{MPa} \sqrt{\mathrm{m}})$ & $\Delta K_{\text {th-eff }}(\mathrm{MPa} \sqrt{\mathrm{m}})$ & $C$ \\
\hline C(T) Cold-Spray 6061-As-Sprayed & 0.1 & 2.2 & 1.4 & $4.2 \mathrm{E}-10$ \\
C(T) Rolled 6061-T6 (Table IV) & 0.1 & 3.8 & 2.2 & 7.6 \\
SF(T) Rolled 6061-T6, Cold-Spray Coated & 0.1 & 1.9 & n/a & 4.11 \\
SF(T) Rolled 6061-T6 (Table IV) & 0.1 & 1.3 & n/a & $4.9 \mathrm{E}-10$ \\
\hline
\end{tabular}

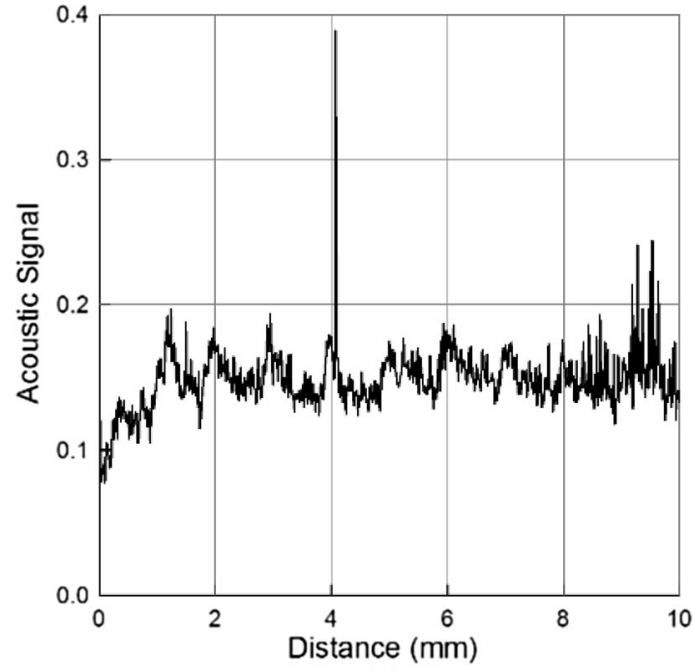

(a)

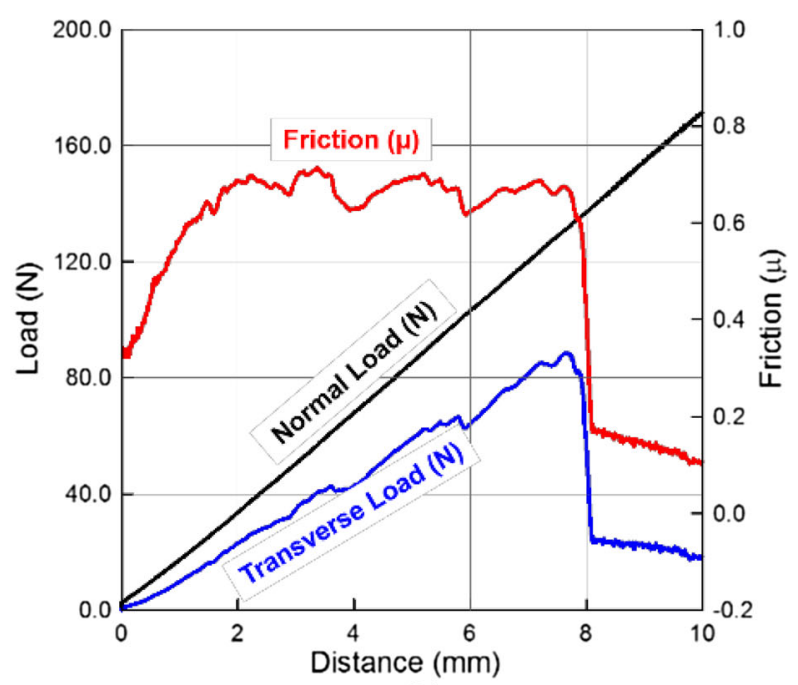

(b)

Fig. 9-Examples of the $(a)$ acoustic signal and $(b)$ friction and normal/transverse loading recorded during scratch testing of as-sprayed cold-spray 6061. 


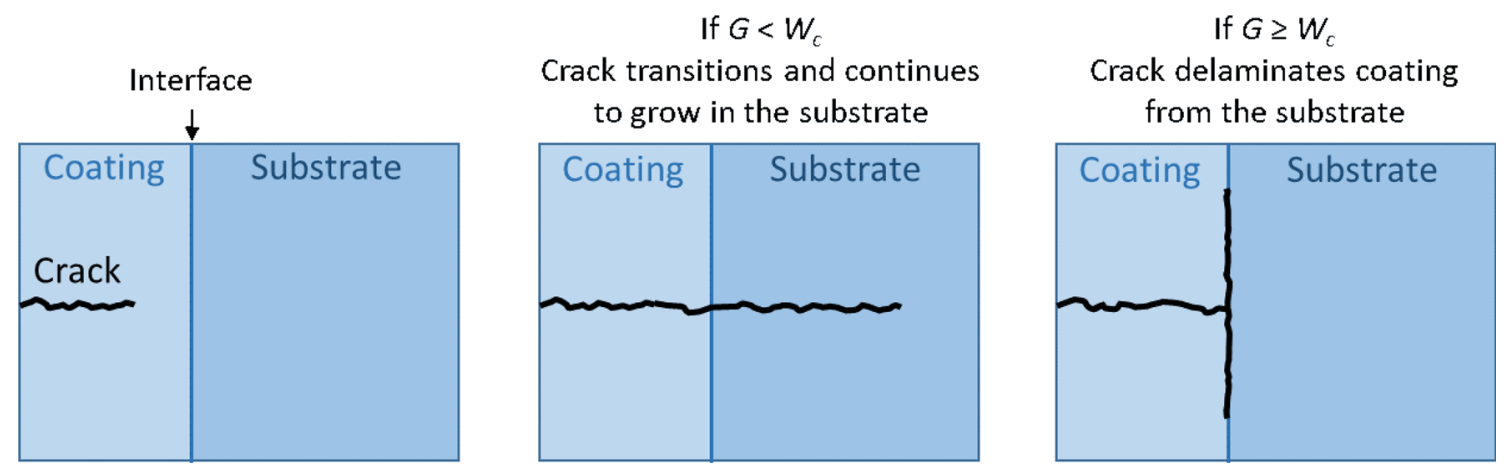

Fig. 10-Schematic representation of crack interaction with the coating-substrate interface.

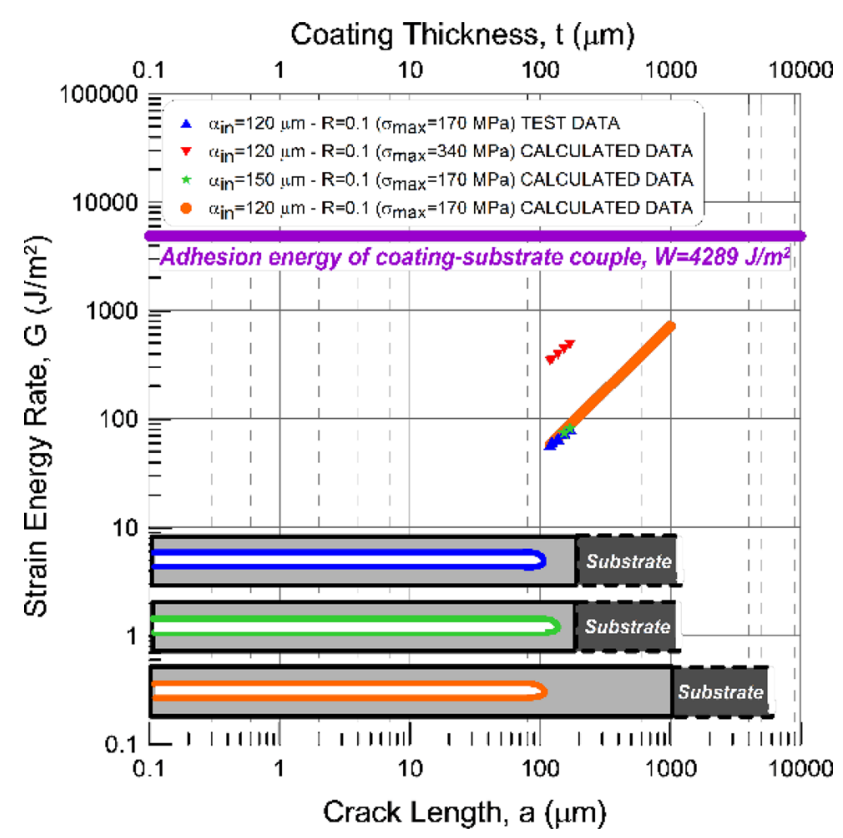

Fig. 11-Crack-interface stability map correlating flaw size and coating thickness to the strain energy release rate. The light gray bars and colored contours in the bottom part of the chart represent coating thickness and initial flaw size, respectively.

$\Delta K_{\mathrm{th}}$ values, as well as Paris Law coefficients ( $C$ and $m$ ), for all tested conditions are summarized in Table V. In the cold-spray-coated $\mathrm{SF}(\mathrm{T})$ specimen, the crack initiates in the as-sprayed material, and has a similar $\Delta K_{\mathrm{th}}$ to the as-sprayed cold-spray $\mathrm{C}(\mathrm{T})$ specimen (i.e., small and long crack growth thresholds are similar, as also observed for the annealed cold-spray material in Figure 5). The applied coating was $150 \mu \mathrm{m}$ thick, and the initial EDM notch was $120 \mu \mathrm{m}$ deep so the crack was roughly $30 \mu \mathrm{m}$ in length when it reached the interface with the substrate, corresponding to a $\Delta K_{\text {app }}$ value of $\sim 2.1 \mathrm{MPa} \sqrt{\mathrm{m}}$, marked by the vertical dashed line in Figure 8. From this transition point forward, as expected, the fatigue crack growth curve of the coated $\mathrm{SF}(\mathrm{T})$ specimen starts progressively converging towards the rolled 6061-T6 $\mathrm{SF}(\mathrm{T})$ data. At $\Delta K$ higher than $\sim 12 \mathrm{MPa} \sqrt{\mathrm{m}}$, both of these curves transition to a long crack growth behavior similar to that of the rolled 6061-T6 C(T) specimen at high $\Delta K$ values.

\section{Scratch testing results and calculation} of deposition-substrate adhesion energy

Although it was verified that the cold-spray coating remains attached to the 6061-T6 substrate during small fatigue crack growth, the adhesion strength could not be quantified directly through the fatigue crack growth testing. Thus, complementary scratch tests were performed for cold-spray depositions on rolled 6061-T6 substrates. The coatings were examined in both conditions (as-sprayed and annealed), but results are presented only for the as-sprayed case as the annealed coating did not produce any distinct acoustic signal that could be associated to a delamination event. This is due to the increased ductility of the annealed coating, which makes recording failure events using scratch testing difficult. Other interfacial characterization methods that can be conducted on more ductile coatings include the bond strength method (ASTM C633-13 $3^{[40]}$ ), the triple lug shear method (MIL-J-24445 $\mathrm{A}^{[41]}$ ), and eddy current sensing ${ }^{[42]}$ which, while currently limited in its application, is particularly attractive due to the non-destructive nature of the testing. From the scratch testing, the critical load, $P$, that causes failure in the coating can be determined (see Figure 9). The critical load represents the load that yields a distinct acoustic signal event, which in the case of the as-sprayed cold-spray 6061, takes place at a scratch length of $4 \mathrm{~mm}$ that corresponds to a critical normal load of $69 \mathrm{~N}$.

The induced compressive stress in the coating during the scratch test that causes failure, $\sigma_{\mathrm{c}}$, can be calculated using Eq. [1] ${ }^{[43]}$

$$
\sigma_{\mathrm{c}}=\frac{0.15}{r}\left(\frac{P H_{\mathrm{c}}}{H_{\mathrm{s}}}\right)^{0.5} E_{\mathrm{c}}^{0.3} E_{\mathrm{s}}^{0.2}
$$

where $r$ is the radius of the indenter; $H_{\mathrm{c}}, H_{\mathrm{s}}, E_{\mathrm{c}}$, and $E_{\mathrm{S}}$ are the hardness and elastic modulus values of the coating and substrate, respectively. Then, the adhesion energy was calculated and compared to the strain energy release rate during small fatigue crack growth, at the interface between the cold-spray coating and 6061-T6 substrate, according to Eq. [2] $]^{[44]}$ and Eqs. [3] and $[4],{ }^{[45,46]}$ respectively. 


$$
W_{c}=K_{2}\left(\sigma_{\mathrm{c}}+\sigma_{\mathrm{R}}\right)^{2} t \frac{1-v_{\mathrm{c}}^{2}}{E_{\mathrm{c}}}
$$

In Eq. [2], $W_{\mathrm{c}}$ is the adhesion energy, and $K_{2}$ is a dimensionless driving force dependent on the cracking pattern. ${ }^{[47]} \mathrm{A} K_{2}$ value of 0.343 was used corresponding to a spalling type of failure that was observed in the cold-spray coatings in this study (spalling is also the cracking pattern associated with the lowest dimensionless driving force, thus providing the most damaging scenario for calculating a conservative estimate of the strain energy release rate). Further, $\sigma_{\mathrm{c}}$ is the critical compressive stress, $\sigma_{\mathrm{R}}$ is the residual stress, $t$ is coating thickness, and $v_{\mathrm{c}}$ and $E_{\mathrm{c}}$ are the Poisson's ratio and elastic modulus of the coating material. These values were obtained from material property data handbooks, and from the mechanical testing performed during this study and in a previous work by the authors. ${ }^{[24]}$

$$
G=\frac{1-v_{\mathrm{c}}^{2}}{E_{\mathrm{c}}}\left(K_{\mathrm{I}}^{2}+K_{\mathrm{II}}^{2}\right)
$$

In Eq. [3], $G$ is the strain energy release rate, and $K_{\mathrm{I}}$ and $K_{\mathrm{II}}$ are the mode I and mode II maximum stress intensity factors. In Eq. [4], $\theta$ is the angle between the applied load and crack propagation directions.

$$
K_{\mathrm{II}}=K_{\mathrm{I}}\left(\frac{\sin (\theta)}{3 \cos (\theta)-1}\right)
$$

Plain strain conditions were assumed for the strain energy release rate calculations. Moreover, the residual stress in the coating was not included in the calculation as it was found during previous residual stress evaluations ${ }^{[24]}$ to be three orders of magnitude lower than the compressive stress that is required to cause failure (a few MPa $v s \sim 2.5 \mathrm{GPa}$ ).

It follows that a growing crack transitioning from the cold-spray coating, or any type of coating for that matter, to the substrate material, will do so without delamination from the coating as long as the strain energy release rate of the crack at the interface, $G$, is lower than the adhesion energy of the coating-substrate pair, $W_{\mathrm{c}}$. If $G$ is greater than $W_{\mathrm{c}}$, then the crack will decohere the coating from the substrate, as shown schematically in Figure 10.

\section{Crack-interface stability maps and coating design} for high-integrity structural applications

The results from the adhesion energy calculations indicate that the coating should be stable during small fatigue crack growth since the strain energy release rate at the coating-substrate interface is significantly lower than the adhesion energy of the coating-substrate couple. For a coating thickness of $150 \mu \mathrm{m}$, the strain energy release rate, $G$, at a maximum cyclic stress of 170 $\mathrm{MPa}$ was calculated as $80 \mathrm{~J} / \mathrm{m}^{2}$ (using the values $v_{\mathrm{c}}=0.33, E_{\mathrm{c}}=67.5 \mathrm{GPa}, K_{\mathrm{I}}=2.47 \mathrm{MPa} \sqrt{\mathrm{m}}$, and $K_{\text {II }}=0.21 \mathrm{MPa} \sqrt{\mathrm{m}}$ ), while the coating-substrate adhesion energy, $W_{\mathrm{c}}$, was found to be equal to $4289 \mathrm{~J} / \mathrm{m}^{2}$ (using the values $K_{2}=0.343,\left(\sigma_{\mathrm{c}}+\sigma_{\mathrm{R}}\right)=2.5 \mathrm{GPa}$, $t=150 \mu \mathrm{m}, v_{\mathrm{c}}=0.33$, and $\left.E_{\mathrm{c}}=67.5 \mathrm{GPa}\right)$. However, the strain energy release rate varies with crack length, as well as applied stress ratio, $R$ (which is affecting $K_{\mathrm{I}}$ and $K_{\mathrm{II}}$ terms). Thus, the variation of the total strain energy release rate, under modes I and II, should be considered with respect to the crack size/coating thickness and stress ratio, $R$. Such a comparison between adhesion energy and strain energy release rate, as a function of crack size and coating thickness, is shown in the crack-interface stability map presented in Figure 11. Different combinations of crack length, coating thickness, and maximum stress amplitude are shown. All of the conditions examined produce strain energy release rates that are orders of magnitude lower than the coating-substrate adhesion energy. It should be noted that this stability map is only based on combinations of coating thickness, flaw size, and stress amplitude. In actual applications, there will other significant factors to consider such as surface roughness and cleanliness, which will affect the coating-substrate adhesion.

From the crack-interface stability map, it can be concluded that the coating should not decohere from the substrate at any point, since the total strain energy release rate, $G$, is lower than the adhesion energy of the coating-substrate couple, confirming the integrity of the interface. Given this valuable information regarding the stability of the interface during fatigue crack growth, the design for fatigue crack growth resistance of coldspray-coated components can be significantly improved. Knowledge of the fatigue crack growth behavior of cold-spray-coated alloys and the adhesion energy of the coating-substrate couple are critical in determining whether the interface is stable or not, under different deposition and application conditions, and can be used as design tools for high integrity. Moreover, this approach can also be used to design repair protocols for structural components using the cold-spray technology.

\section{CONCLUSIONS}

Several significant findings and developments resulted from this study, and a summary of the conclusions is presented here:

- Cold-spray alloys exhibit higher small crack growth thresholds, and hence better fatigue crack growth resistance, than rolled alloys due to their finer microstructure, which provides more grain boundaries that act as barriers in the early stages of crack propagation, as well as differences in the distribution, concentration, and morphology of the precipitate and dispersoid phases.

- The annealed cold-spray 6061 material was found to have similar threshold values in both small and long fatigue crack growth due to low levels of crack closure, which is again due to the fine microstructure of the cold-spray material. In contrast, the difference in thresholds for small and long fatigue crack growth in the rolled 6061-T6 is much larger, indicating 
higher levels of closure due to the coarse microstructure.

- The annealed cold-spray 6061 material showed similar small and long fatigue crack growth thresholds; the fracture surface was faceted and crack growth was transparticular. The low Region II crack growth was also similar in both small and long fatigue crack growth specimens, characterized by a mixed mode of transparticular and interparticular crack growth.

- The long and small fatigue crack growth of the rolled 6061-T6 alloy is characterized in the near-threshold regime by a transgranular fracture mode with a faceted appearance. The low Region II long and small crack fracture surfaces show cleavage planes and steps resulting from the brittle, transgranular crack propagation.

- The interfacial stability was examined in cold-spray 6061-rolled 6061-T6 couples. It was found that the coating remains attached to the substrate with no delamination during cyclic loading, at low and positive $R$ ratio.

- An original method of quantifying the deposition-substrate interfacial strength, as well as correlating it to the response under cyclic loading, via the crack-interface stability maps, was introduced. Based on this method, failure at the coating-substrate interface can be predicted during crack growth under cyclic loading using a combination of metallurgical parameters related to the cold-spray process, and fracture mechanics definitions.

- The new methodology for interfacial evaluation can be applied to cold-spray depositions and other coatings with low to intermediate ductility, and can be used to design the material and process for performance and reliability in structural components and repairs.

\section{ACKNOWLEDGMENTS}

The authors thank the consortium members of the Integrative Materials Design Center at Worcester Polytechnic Institute, especially the Army Research Laboratory (ARL), for their support of this work and valuable technical contributions.

\section{OPEN ACCESS}

This article is distributed under the terms of the Creative Commons Attribution 4.0 International License (http://creativecommons.org/licenses/by/4.0/), which permits unrestricted use, distribution, and reproduction in any medium, provided you give appropriate credit to the original author(s) and the source, provide a link to the Creative Commons license, and indicate if changes were made.

\section{REFERENCES}

1. A. Papyrin: Adv. Mater. Process., 2001, vol. 159, pp. 49-51.

2. V. Champagne and D. Helfritch: Int. Mater. Rev., 2016, vol. 61, pp. $437-55$.

3. A.J.G. Lunt, N. Baimpas, E. Salvati, I.P. Dolbnya, T. Sui, S. Ying, H. Zhang, A.K. Kleppe, J. Dluhos, and A.M. Korsunsky: J. Strain Anal., 2015, vol. 50, pp. 426-44.

4. V. Champagne, D. Helfritch, P. Leyman, R. Lempicki, and S. Grendahl: Modell. Simul. Mater. Sci. Eng., 2005, vol. 13, pp. 1119-28.

5. H. Assadi, F. Gartner, T. Stoltenhoff, and H. Kreye: Acta Mater., 2003, vol. 51, pp. 4379-94.

6. M. Grujicic, C. Zhao, W. DeRosset, and D. Helfritch: Mater. Des., 2004, vol. 25, pp. 681-88.

7. V. Champagne, D. Helfritch, S. Dinavahi, and P. Leyman: $J$. Therm. Spray Technol., 2011, vol. 20, pp. 425-31.

8. F. Raletz, M. Vardelle, and G. Ezo'o: Surf. Coat. Technol., 2006, vol. 201, pp. 1942-47.

9. M. Grujicic, J. Saylor, D. Beasley, W. Derosset, and D. Helfritch: Appl. Surf. Sci., 2003, vol. 219, pp. 211-27.

10. T. Hussain, D.G. McCartney, P.H. Shipway, and D. Zhang: $J$. Therm. Spray Technol., 2009, vol. 18, pp. 364-79.

11. T. Schmidt, F. Gartner, H. Assadi, and H. Kreye: Acta Mater., 2006, vol. 54, pp. 729-42.

12. V. Champagne: The Cold Spray Materials Deposition Process: Fundamentals and Applications, 1st ed., Woodhead Publishing Limited, Cambridge, 2007

13. P. Cavaliere and A. Silvello: Int. J. Adv. Manuf. Technol., 2015, vol. 81, pp. 1857-62.

14. E. Sansoucy, G.E. Kim, A.L. Moran, and B. Jodoin: J. Therm. Spray Technol., 2007, vol. 16, pp. 651-60.

15. G Kim, B Jodoin, and E Sansoucy: Patent Application No. PCT/ CA2007/001967, 2008.

16. R. Ghelichi, D. MacDonald, S. Bagherifard, H. Jahed, M. Guagliano, and B. Jodoin: Acta Mater., 2012, vol. 60, pp. 6555-61.

17. R. Ghelichi, S. Bagherifard, D. MacDonald, M. Brochu, H. Jahed, B. Jodoin, and M. Guagliano: Int. J. Fatigue, 2014, vol. 65, pp. $51-57$.

18. A. Moridi, S.M. Hassani-Gangaraj, S. Vezzú, L. Trško, and M. Guagliano: Surf. Coat. Technol., 2015, vol. 283, pp. 247-54.

19. W. Sun, A. Wei Yee Tan, N. Win Khun, I. Marinescu, and E. Liu: Surf. Coat. Technol., 2016, vol. 320, pp. 452-57.

20. S. Suresh and R.O. Ritchie: Int. Metals Rev., 1984, vol. 29, pp. 445-75.

21. R.O. Ritchie and J. Lankford: Mater. Sci. Eng., 1986, vol. 84, pp. 11-16.

22. D.A. Lados, D. Apelian, P. Paris, and J. Donald: Int. J. Fatigue, 2005, vol. 27, pp. 1463-72.

23. D.A. Lados, D. Apelian, and J.K. Donald: Acta Mater., 2006, vol. 54 , pp. 1475-86.

24. A. Gavras, D.A. Lados, V. Champagne, and R.J. Warren: Int. J. Fatigue, 2018, vol. 110, pp. 49-62.

25. T. Schmidt, H. Assadi, F. Gartner, H. Richter, T. Stoltenhoff, H. Kreye, and T. Klassen: J. Therm. Spray Technol., 2009, vol. 18, pp. 794-808.

26. F. Gartner, C. Borchers, T. Stoltenhoff, H. Kreye, and H. Assadi: Therm. Spray 2003, Proc. Int. Therm. Spray Conf., 2003, vol. 2, pp. $1-8$.

27. ASTM Standard E112-12: Standard Test Methods for Determining Average Grain Size, ASTM International, West Conshohocken, 2012.

28. R.A. Jeniski, Jr.: Mater. Sci. Eng. A, 1997, vol. 237, pp. 52-64.

29. D. Belsito, B. McNally, L. Bassett, V. Champagne, and R. Sisson: Materials Science and Technology Conference and Exhibition 2013 (MS\&T'13), 2013, vol. 1, pp. 1729-36.

30. ASTM Standard E384-11: Standard Test Method for Knoop and Vickers Hardness of Materials, ASTM International, West Conshohocken, 2011.

31. ASTM Standard E8M-16a: Standard Test Methods for Tension Testing of Metallic Materials, ASTM International, West Conshohocken, 2016.

32. ASTM Standard E647-15: Standard Test Method for Measurement of Fatigue Crack Growth Rates, ASTM International, West Conshohocken, 2015. 
33. A.K. Vasudeven: Mater. Sci. Eng. A, 1994, vol. 188, pp. 122.

34. ASTM Standard STP 486: Damage Tolerance in Aircraft Structures, ASTM International, West Conshohocken, 1971, pp. 230-42.

35. K. Donald: Int. J. Fatigue, 1997, vol. 19, pp. 191-95.

36. K. Donald: Fatigue Fract. Mech., 1999, vol. 29, pp. 674-95.

37. ASTM Standard C1624-05: Standard Test Method for Adhesion Strength and Mechanical Failure Modes of Ceramic Coatings by Quantitative Single Point Scratch Testing, ASTM International, West Conshohocken, 2015.

38. ASTM Standard E3-11: Standard Guide for Preparation of Metallographic Specimens, ASTM International, West Conshohocken, 2017.

39. Buehler, an ITW Company: Buehler ${ }^{\circledR}$ SumMet ${ }^{T M}$ : The Sum of Our Experience: A Guide to Materials Preparation and Analysis, 2nd ed., Buehler, an ITW Company, Lake Bluff, 2013.
40. ASTM Standard C633-13: Standard Test Method for Adhesion or Cohesion Strength of Thermal Spray Coatings, ASTM International, West Conshohocken, 2017.

41. Miltary Specification MIL J-24445A: Joint, Bimetallic Bonded, Aluminum to Steel, U.S. Department of Defense, Washington, 1977.

42. ASTM Standard E2338-11: Standard Practice for Characterization of Coatings Using Conformable Eddy-Current Sensors without Coating Reference Standards, ASTM International, West Conshohocken, 2011.

43. K. Pappacena, D. Singh, O. Ajayi, J. Routbort, O. Erilymaz, N. Demas, and G. Chen: Wear, 2012, vols. 278-279, pp. 62-70.

44. J.W. Hutchinson and Z. Suo: Adv. Appl. Mech., 1992, vol. 29, pp. 63-191.

45. F. Erdogan and G. Sih: J. Basic Eng., 1963, vol. 85, pp. 519-25.

46. B. Cotterell: Int. J. Frac. Mech., 1966, vol. 2, pp. 526-33.

47. A.G. Evans, M.D. Dory, and M.S. Hu: J. Mater. Res., 1988, vol. 3, pp. 1043-49. 